\title{
CONF-970675--1
}

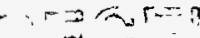

\section{ADMIXTURE ENHANCED CONTROLLED LOW-STRENGTH MATERIAL FOR DIRECT UNDERWATER INJECTION WITH MINIMAL CROSS- CONTAMINATION}

REFERENCE: Hepworth, H. K., Davidson, J. S., and Hooyman, J. L., “Admixture Enhanced Controlled Low-strength Material for Direct Underwater Injection with Minimal Cross-contamination," The Design and Application of Controlled LowStrength Materials (Flowable Fill), ASTM STP 1269, A. K. Howard and J. L. Hitch, Eds., American Society for Testing and Materials, Philadelphia, 1997.

ABSTRACT: Commercially available admixtures have been developed for placing traditional concrete products under water. This paper evaluates adapting anti-washout admixture (AWA) and high range water reducing admixture (HRWRA) products to enhance controlled low-strength materials (CLSMs) for underwater placement. A simple experimental scale model (based on dynamic and geometric similitude) of typical grout pump emplacement equipment has been developed to determine the percentage of cementing material washed out. The objective of this study was to identify proportions of admixtures and underwater CLSM emplacement procedures which would minimize the cross-contamination of the displaced water while maintaining the advantages of CLSM. Since the displaced water from radioactively contaminated systems must be subsequently treated prior to release to the environment, the amount of cross-contamination is important for cases in which cementing material could form hard sludges in a water treatment facility and contaminate the in-place CLSM stabilization medium.

KEYWORDS: tank stabilization, controlled density fill, controlled low-strength material, admixture, anti-washout admixture, water reducing admixture, flowable mortar, low density material, unshrinkable fill, void filling

${ }^{1}$ Professor Emeritus of Engineering, Northern Arizona University.

${ }^{2}$ Waste Management and Remedial Action Division, Oak Ridge National Laboratory, Oak Ridge, Tennessee. 


\section{DISCLAIMER}

Portions of this document may be illegible in electronic image products. Images are produced from the best available original document. 


\section{INTRODUCTION}

This paper addresses development of a suitable stabilizing packing material for interim in-situ remediation of tanks, vaults, and other underground structures with partial to wholly flooded void spaces. To satisfy regulatory requirements, all subterranean void spaces would need to be filled with a stabilizing material. Since waste management and environmental restoration interim remediation work often involves stabilizing contaminated structures, the filling medium of choice should possess characteristics which (1) minimally interfere with future dismantlement of a treated facility, (2) exhibit reasonable structural stability, (3) contribute to the well-being of the environment, and (4) cost less than other viable alternatives.

This study investigated commercially available admixtures to enhance a locally available CLSM grout mixture and an injection procedure to allow placement of this material under-water. During the injection process, CLSM should accomplish the following: (1) displace the water, causing it and accumulated soft sludges (sp gr $<1.5$ ) to float at the liquid grout interface, (2) maintain its self leveling characteristic (i.e., fill voids below the interface), and (3) hydrate to its designed low strength and low permeability. Operationally, the displaced solution and sludges are to be simultaneously removed as they are displaced and moved closer to the tank's access port. This admixture will assist in the interim remediation of liquid low-level (radioactive) waste inactive tanks and underground storage tanks containing difficult-to-remove aqueous-based inventories.

This study evaluated and selected admixtures for optimizing underwater injection of CLSM. Candidates tested are anti-washout admixtures, water-reducing admixtures, and pump-assisting admixtures. The objective is to prevent or mitigate cross contamination by investigating types and proportions of admixtures and underwater CLSM emplacement procedure.

\section{Background}

The U.S. Army Corps of Engineers has sponsored programs to develop away for underwater (ocean, brackish, or freshwater) emplacement of high-strength concrete materials. The strength of the concrete must be maintained while ensuring water and concrete contamination control. These programs have produced additives which are adequate to allow the emplacement of concrete under tidewater conditions and to line or repair locks, dams, or canals without curtailing boat traffic or draining the facility.

CLSM is a cement-based material recognized by the American Concrete Institute (ACD), with oversight responsibility assigned to Committee 229. CLSM is defined by Cement and Concrete Terminology (ACI 116R) as material that exhibits "an unconfined ultimate compressive strength of 1,200 pounds per square inch (psi) or less." In fact, most current CLSM applications specify compressive strengths of approximately $2 \mathrm{kPa}$ (300 psi) or less. This lower strength specification is to allow for future excavation of the material. CLSM is a member of the grout class of materials, is self-compacting, and was developed to replace compacted soil as a backfill medium. Traditional compaction of soil is labor intensive and presents difficulty with maintaining adequate quality control, whereas CLSM achieves its properties through the design and control of its constituent 
mix and hydration process. Its composition uses traditional concrete grout constituents: Portland cement, sand, and water, with fly ash an added ingredient. CLSM benefits the environment since it makes use of a previously wasted by-product from coal-fired electric utility power plants. CLSM has been demonstrated to be very geologically stable (does not swell or contract like bentonite clays), is reversible (can be removed by traditional excavation methods) and maintains a low permeability to groundwater intrusion.

CLSM has been successfully used at the Oak Ridge National Laboratory (ORNL) in the interim remediation of several tanks requiring governmental regulatory approved processes. Empty tanks with cut and capped pipelines were filled to capacity with CLSM. If a tank had been removed from an underground vault, then vault space was satiated with CLSM. Fly ash based CLSM offers many advantages for environmental restoration stabilization applications:

1. It is economical and readily available.

2. It is easy to install and self-leveling, fills all void spaces (flows and/or pumps with ease).

3. It does not settle after hydration (during placement and hydration process, CLSM settlement is approximately $1 \mathrm{~cm}$ per vertical meter $[1 / 8$ in. per vertical foot]).

4. The hydrated material is nonhazardous to the environment.

5. It possesses low permeability $\left(1.5 \times 10^{-5} \mathrm{~cm} / \mathrm{s}\right)$.

6. It is easily remediated in the future (excavatable with conventional digging equipment).

Hence, CLSM is useful for interim remediation or stabilization by entombing contaminated and/or radioactive facilities and equipment.

Stabilization of water-shielded or -inundated structures--In many instances during restoration of nuclear facilities, water is used to shield a contaminated hazard. To protect workers and delicate equipment from radioactive components, water is frequently used as a radiation shield or barrier. Shielding examples are (1) reactor pools and canals used to transport or store spent nuclear fuel elements, irradiated and activated materials, and experimental apparatus, and (2) canals used to transport contaminated filters removed from nuclear facility ventilation systems. (Note: with age, facility surfaces become contaminated [e.g., dissolved contaminants diffuse into a pool's concrete walls].)

If a structure is inundated, it may be impractical or costly to remove water before installing CLSM as a stabilizing agent. It is impractical and potentially hazardous to the environment to isolate breached underground tanks located below the groundwater table. (Groundwater will replenish water pumped from the tank, or artificial lowering of the water table will permit tankage water and accumulated sludge to migrate, further polluting the environment.)

An alternative to removing water or tankage solution is to simultaneously place CLSM at the bottom of the confined space and pump or bleed off displaced water and accumulated sludges. However, in its uncured or plastic state, traditional CLSM components are quite susceptible to suspension in water, so its injection under water 
allows a cross-contamination via water migrating into and cementing products washing out of the CLSM. During material injection, turbulence or mixing is an aggravating influence for this undesirable interchange and should be minimized.

\section{Program Objectives}

1. Eliminate or minimize cross-contamination of tankage water with emplaced CLSM. This is important since cementing materials carried with displaced contaminated water solution to storage tanks or the treatment facility could result in formation of a hard sludge deposit. Furthermore, contamination of emplaced CLSM stabilization material would leave a legacy remnant, and if remediated by excavation in the future, the CLSM would be treated as a higher level radioactive solid waste.

2. Maintain the following advantages of the CLSM:

- Low permeability $\left(<1.5 \times 10^{-5} \mathrm{~cm} / \mathrm{s}\right)$ and high specific gravity (sp gr $\sim 2.1$ )

- Future remediation by excavation using standard digging implements

- Void filling and ease of placement in cramped, contaminated, or hard-to-access facilities (i.e., tanks)

- Low cost and availability of emplacement technologies and equipment

\section{Definitions}

- Anti-washout Admixture (AWA) [1] - A water-soluble polymer which physically binds the mixing water with the cementitious materials. AWAs are principally designed to enhance the stability of concrete used in underwater applications.

- Bleeding - The separation of liquid constituents from the concrete product while it is in a plastic state (1. external bleeding - separation of liquids from the concrete interface, 2. internal bleeding - collection of liquids in channels or around embedments).

- Consistency - A measure of the flowability of a cement product while in its fluid state. This study used the modified flow consistency test procedure.

- High Range Water Reducing Admixture (HRWRA) [1] - An additive designed for concrete products to maintain high fluidity without impairing strength or durability.

- Permeability $[2,3]$ - A material coefficient, $k$, relating the flow of a fluid through a porous medium. Permeability is defined as follows:

$$
\mathrm{k}=\frac{\mathrm{Q}}{\mathrm{A} \frac{\mathrm{dh}}{\mathrm{d} \ell}}
$$

where: $\mathrm{k}$ - permeability coefficient $(\mathrm{cm} / \mathrm{s})$

Q - volume flux $\left(\mathrm{cm}^{3} / \mathrm{s}\right)$

A - normal cross-sectional flow area $\left(\mathrm{cm}^{2}\right)$

$\frac{\mathrm{dh}}{\mathrm{d} \ell}$ - fluid piezometric gradient (h- piezometric head [cm], and $\ell$ - direction of flow spatial coordinate $[\mathrm{cm}])$ 
- Pump Assisting Admixtures [4] - A polymeric viscosity regulator additive for grout types of concrete products to enhance their transportability through pumps.

- Washout - A measure of the solid fines (cementitious and sand) components flushed out and suspended in the surrounding water medium when a cement product is injected under-water.

\section{SPECIFICATIONS, THEORY, AND PROCEDURES}

\section{Admixtures}

This study evaluates commercially available AWA, HRWRA, and pump-assisting admixtures applied to very flowable CLSM. Khayat [5] cautions industrial users of AWA and HRWRA products to ensure chemical compatibility when used in combination. The products of two suppliers ${ }^{\dagger}$ were chosen for this investigation:

Master Builders, Inc.

23700 Chagrin Boulevard

Cleveland, Ohio 44122-5554

(216) $831-5500$

$\begin{array}{lll}\text { AWA - } & \text { Rheomac }^{\otimes} \text { UW 450 } & \text { (chemical family: modified cellulose ether) } \\ \text { HRWRA - Rheobuild } & \text { 2000B } & \text { (chemical family: melamine polymer) }\end{array}$

Sika Corporation

201 Polito Avenue

Lyndhurst, New Jersey 07071

(201) 933-8800

AWA - Sikament ${ }^{\circledR} 100$ SC (chemical family: sulfonated naphthalene and melamine polymer)

HRWRA - Sikament ${ }^{\circledast} 10 \mathrm{ESL}$ (chemical family: sulfonated vinyl copolymer, sodium salt)

Pump - Sika Pump VP (chemical characterization: water-based polymer for viscosity regulation)

${ }^{\dagger}$ Reference to any specific commercial product, process, or service by trade name, trademark, manufacture, or otherwise does not constitute or imply its endorsement, recommendation, or favoring by the United States Government or agency thereof.

${ }^{\circledR}$ Rheomac and Reheobuild are registered trademarks of Sandoz, Ltd.

${ }^{\circledR}$ Sikament is registered trademark of Sika Corporation. 
Obtaining a National Environmental Policy Act - Categorical Exclusion approval substantially reduced the time authorized for the experimental portion of the program. Hence, to complete the program on schedule and to ensure compatibility, manufacturers' products were not intermingled.

\section{Test Equipment and Apparatus}

Two tests were conducted for each CLSM test mixture: a consistency test and an washout test.

Modified Flow Consistency Test [4]--Place an open-ended cylinder $(7.62 \mathrm{~cm}$ [3 in.] in diameter by $15.24 \mathrm{~cm}$ [ 6 in.] long) vertically on a smooth level surface. Fill the cylinder flush to its top with CLSM. Lift the cylinder vertically, allowing CLSM to flow onto the level surface. Good flowability is achieved if there is no noticeable segregation and if the material spreads at least $20 \mathrm{~cm}(8 \mathrm{in}$.) in diameter.

Washout Test--There is a standardized washout test for relatively high-strength stiff (low slump) concrete (Army Corps of Engineers Test Method for Determining the Resistance of Freshly Mixed Concrete to Washing Out in Water, CRD C 61 [6, 7]). This test consists of filling a perforated steel basket with a 2-kg sample of fresh concrete, then allowing the basket to free-fall through a test column filled with $1.7 \mathrm{~m}$ of water. After three drop tests, the loss of mass is measured. This washout test is not an adequate model for the free-flowing CLSM required to fill tanks, vaults and canals.

All constituent CLSM materials used in these tests are sifted through a sieve with a 6-per-cm (16-per-in.) mesh. The consistency to ensure adequate flow in filling inundated tanks and voids is in the range of $30 \mathrm{~cm}(12 \mathrm{in}$.) or above (for injecting underwater). A test rig which models the salient aspects of the pumping and injection process for CLSM into a tank with a quiescent water inventory was developed. The test fixture devised uses geometric and dynamic simulation to model a realistic, but severe, injection process.

\section{Design for CLSM Anti-washout Test Rig}

The test rig is approximately $1 / 8$ scale. Commercial grout pumps typically use a $6.35 \mathrm{~cm}$ (2.5 in.) internal diameter hose to deliver approximately $95 \mathrm{~L} / \mathrm{min}(25 \mathrm{gal} / \mathrm{min})$ of grout (i.e., 8 minutes to pump $0.75 \mathrm{~m}^{3}$ [one cubic yard] of grout). Note that $95 \mathrm{~L} / \mathrm{min}$ was baselined since water removal is to occur simultaneously with CLSM injection, and most ORNL liquid transfer lines are designed as gravity drains constructed of 5-cm [2-in.] schedule 40 pipe. Grout pumps are of positive displacement design, resulting in a pulsating flow with operating frequency dependent on drive engine speed. To simulate this pulsating action, a positive displacement peristaltic pump was used. The peristaltic pump selected is a Watson Marlow PumpPro model DPM, operating with an 8.0-mm internal diameter tube.

The Watson Marlow PumpPro DPM peristaltic pump operating speed range is user programmable to operate from 3 to $300 \mathrm{r} / \mathrm{min}$ and when equipped with an $8-\mathrm{mm}$ bore 
tube, it provides from $30 \mathrm{~mL} / \mathrm{min}$ to $3.0 \mathrm{~L} / \mathrm{min}$. Marprene tubing was selected for use with this pump due to its elasticity. Considering the flowability range of the CLSM to be tested, the operation of the pump was programmed at a speed of $200 \mathrm{r} / \mathrm{min}$, and the quantity pumped was $2 \mathrm{~L}$. These settings provided a pump volume flow rate of approximately $2 \mathrm{~L} / \mathrm{min}$.

Geometric Similarity--Speed of $94.6 \mathrm{~L} / \mathrm{min}(25 \mathrm{gal} / \mathrm{min})$ of CLSM through a 6.35-cm (2.5-in.) internal diameter grout pump transport tube is:

$$
|\overline{\mathrm{V}}|_{\mathrm{G}}=\frac{(94.6 \mathrm{~L} / \mathrm{min})\left(10^{3} \mathrm{~cm}^{3} / \mathrm{L}\right)}{(60 \mathrm{~s} / \mathrm{min})\left(\frac{\pi(6.35)^{2} \mathrm{~cm}^{2}}{4}\right)}=49.7 \mathrm{~cm} / \mathrm{s} \quad(1.63 \mathrm{ft} / \mathrm{s})
$$

The speed of $2 \mathrm{~L} / \mathrm{min}(0.528 \mathrm{gal} / \mathrm{min})$ of CLSM through an 8-mm (0.3125-inch) internal diameter peristaltic pump Marprene tube is:

$$
\begin{aligned}
& |\overline{\mathrm{V}}|_{\mathrm{P}}=66.3 \mathrm{~cm} / \mathrm{s} \quad(2.18 \mathrm{ft} / \mathrm{s}) \\
& \text { Geometric Similarity }=\frac{|\overline{\mathrm{V}}|_{\mathrm{G}}}{|\overline{\mathrm{V}}|_{\mathrm{P}}}=\frac{49.7}{66.3}=0.75
\end{aligned}
$$

Dynamic Similitude--Based on the Reynolds Number of CLSM flowing through a transport tube:

$$
\text { Reynolds Number }\left(\mathrm{N}_{\mathrm{Re}}\right)=\frac{\text { Inertial Forces }}{\text { Viscous Forces }}=\frac{\mathrm{VD}}{v}=\frac{4 \mathrm{Q}}{\pi \mathrm{D} v}
$$

$$
\text { where: } \begin{aligned}
V & - \text { fluid speed } \\
Q & - \text { fluid volume flux } \\
D & - \text { tube internal diameter } \\
V & - \text { fluid kinematic viscosity }
\end{aligned}
$$

Dynamic Similitude $=\frac{\text { Reynolds Number }\left(\mathrm{N}_{\mathrm{Re}}\right)_{\mathrm{G}}}{\text { Reynolds Number }\left(\mathrm{N}_{\mathrm{Re}}\right)_{\mathrm{P}}}$

$$
=\frac{\frac{4 Q_{G}}{\pi D_{G} v_{C L S M}}}{\frac{4 Q_{p}}{\pi D_{P} v_{C L S M}}}=\frac{Q_{G} D_{P}}{Q_{P} D_{G}}=5.95
$$


Both the geometric similarity and dynamic similitude scale factors are within one order of magnitude, indicating that the peristaltic pump apparatus should adequately model a grout pump.

\section{Washout Experimental Apparatus}

Figure 1 illustrates the model flow apparatus to quantitatively measure and qualitatively observe washout during an injection process. The flow apparatus has been constructed to simulate a proposed tank remediation fill process. The model is designed to continuously inject CLSM at the rate of $2 \mathrm{~L} / \mathrm{min}$ through an 8 - $\mathrm{mm}$ tube. The model simulates an injection process as modeling (1) the start of an underwater injection process by allowing a $2.5-\mathrm{cm}$ free fall of the trial mix jet stream, and (2) the free flow of the CLSM as it spreads by causing the trial mix stream to flow down a 30.5-cm (12-in.) slide inclined at $40^{\circ}$. The slide then terminates into a landing region designed to accumulate $2 \mathrm{~L}$. The injection process provides a flow speed of $0.66 \mathrm{~m} / \mathrm{s}$ for a one-minute period. This design exposes an approximate trial mix surface area of $0.5 \mathrm{~m}^{2}$ to the water in the test tank during the trial mix's free fall and slide. The landing area's configuration allows determination of the equilibrium slope of the test mixture's free surface. This measurement provides a quantitative comparison of the flowability of the test mixtures under-water. To determine the mass fraction of trial mix washed out, the experimental apparatus is equipped with a sampling tube which is elevated $2.5 \mathrm{~cm}(1 \mathrm{in}$.) above the slide. The sample tube draws fluid through two orifices drilled in the tube. These ports are located $25 \mathrm{~cm}$ (10 in.) down the incline from the injection port. The sampling tube is connected to a siphon leading to a $2-\mathrm{L}$ sample collection beaker.

\section{RESULTS}

Mass Washout Percent Determination and Explanation

During a washout test, a cloud (more aptly termed a fog or smog layer) is formed by the particulate matter and the AWA and HRWRA compounds in the CLSM. The cloud is apparently of higher specific gravity than the surrounding water since it forms a definite and clearly visible interface.

The density of the cloud layer varies slightly from bottom to top; however, for analytical purposes the cloud was assumed to be represented by the integrated sample drawn from the sample tube during the washout test. (Note: the tank has been very carefully calibrated in volume percent, $0 \%$ at the bottom to $100 \%$ at the fill level.) The incompressible continuity equation was applied to account for the small variability in quantity of CLSM pumped from test to test. This variability is explained by the CLSM's apparent viscosity variation and the pump's reliance on tubing elasticity to draw CLSM into the tube volume from the supply hopper during a pumping cycle (intake time $<0.15$ seconds per occluding stroke). 


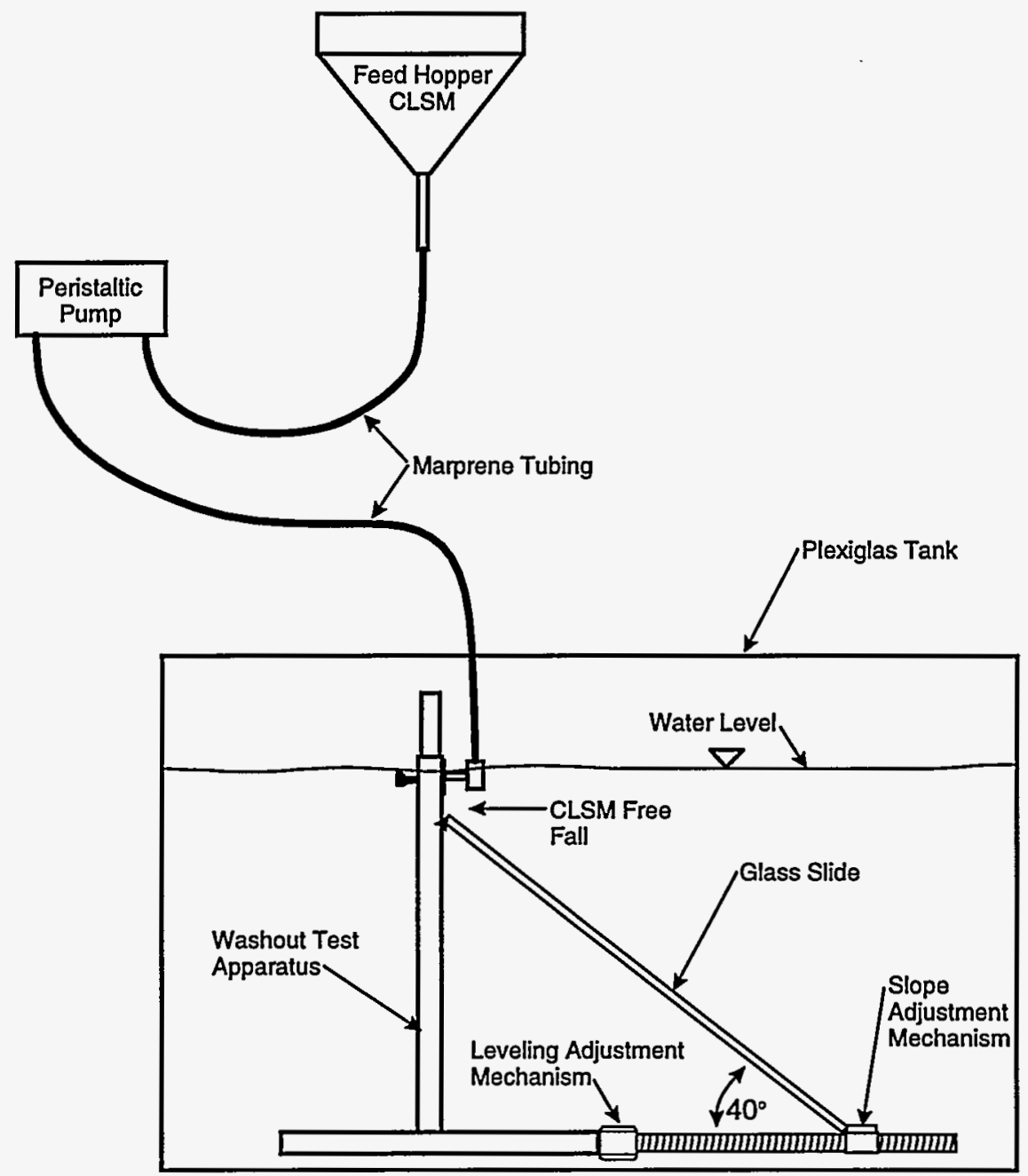

Figure 1

Washout experimental test apparatus

A comparative washout mass is determined by the following volume balance:

$$
\begin{aligned}
& \text { Washout Mass Fraction }(\%)=\frac{\text { Projected CLSM Mass Washout }}{\text { CLSM Mass Injected }} \\
& =\frac{(\text { Filtered Washout) (Tank Clouding) (Tank Volume [Vol.]) }}{\text { (Vol. Siphoned)(CLSM Density)[Vol. Siphoned - }(\Delta \text { Tank Level)(Tank Area)] }} \\
& =\frac{\text { (Filtered Washout) (Tank Clouding) }(0.0067)}{2-(\Delta \text { Tank Level) }(1.226)}
\end{aligned}
$$

where: Filtered washout is in grams.

Tank clouding is in percent.

Tank level is in centimeters. 
The washout mass was collected and filtered to determine the mass of washout collected. Filters were thoroughly dried and weighed before and after each test.

\section{Determination of the Relative Free Surface Slope}

The relative slope of the free surface was measured after each test as water was siphoned from the tank. An indicator mark was located on the tank $7.6 \mathrm{~cm}$ ( 3 in.) from its right end. As the water was slowly siphoned from the tank, its level was measured as the CLSM free surface was exposed at the indicator mark and again as the surface was exposed at the tank's right end.

The measured difference is the CLSM rise, which is divided by a run of $7.6 \mathrm{~cm}$ (3 in.). The appearance of the surface was noted to ensure minimal segregation and uniformity of the exposed surface, with any anomalies noted on the data sheet.

\section{Trial Mix Design}

This study focuses on the consistency and washout behavior of CLSM. The test sequence was as follows: (1) measure and blend the trial mix constituents, (2) perform the consistency evaluation, and (3) execute the washout trial. The CLSM formulation used for these tests was chosen to provide similar compressive stress strength ( $\sigma \approx 100 \mathrm{psi}$ ) and permeability $\left(\mathrm{k} \approx 2.5 \times 10^{-5} \mathrm{~cm} / \mathrm{s}\right)$, which is typical of the commercial product used to remediate empty tanks and vaults at ORNL. Typically the CLSM constituents' blend, per $0.75 \mathrm{~m}^{3}$ (cubic yard), is $22.7 \mathrm{~kg}(50 \mathrm{lb})$ of Portland cement, $272.4 \mathrm{~kg}(600 \mathrm{lb})$ of Type $\mathrm{F}$ fly ash, $1089.6 \mathrm{~kg}(2,400 \mathrm{lb})$ of dry sand. Masonry sand was substituted for the coarse cement sand due to the small size of the peristaltic pump transfer tube. Water and admixtures were varied to determine the effects on consistency and washout. Typically, these mixtures consist of the following per cubic yard: $22.7 \rightarrow 45.4 \mathrm{~kg}(50 \rightarrow 100 \mathrm{lb})$ Portland cement, around $272 \mathrm{~kg}(600 \mathrm{lb})$ of Type F fly ash, $1090 \rightarrow 1270 \mathrm{~kg}$ $(2,400 \rightarrow 2,800 \mathrm{lb})$ of cement sand, and $170 \rightarrow 227 \mathrm{~L}(45 \rightarrow 60$ gal) of water.

To minimize waste, the quantity of each test mixture was designed to produce $3 \mathrm{~L}$. This quantity was sufficient to perform all required tests, with enough residual to ensure that some spillage could be tolerated. This test eliminated the following variables by fixing them as constant throughout the test matrix:

\section{Constituent \\ Portland cement (Type I, II)}

Fly ash

Dry masonry sand
Mass Quantity
$0.0708 \mathrm{~kg}$
$0.8544 \mathrm{~kg}$
$3.1250 \mathrm{~kg}$

Note: The fly ash used is Type F obtained from the Tennessee Valley Authority John Sevier Power Plant. Each constituent was oven dried $\left(12\right.$ hours at $\left.120^{\circ} \mathrm{C}\left[250^{\circ} \mathrm{F}\right]\right)$ and thoroughly sifted through a mesh sieve before being added to test mixture, according to the procedure prescribed in the test plan. Water, HRWRA, and AWA were carefully measured and added to the trial mixture to produce the quality control required for the test. 


\section{CLSM Test Results}

The results are arranged in Tables $1-4$ by similar modified flow consistency test diameters (nominal diameter $\pm 3 \mathrm{~cm}$ or 1 in.).

TABLE 1 - Test results with nominal $25 \mathrm{~cm}$ (10 in.) consistency flow diameter

\begin{tabular}{|c|c|c|c|c|c|c|c|c|c|}
\hline \multirow{2}{*}{$\begin{array}{c}\text { Mixture } \\
\#\end{array}$} & \multicolumn{2}{|c|}{$\begin{array}{l}\text { Consistency } \\
\text { Diameter }\end{array}$} & \multirow{2}{*}{$\begin{array}{l}\text { Water } \\
(\mathrm{mL})\end{array}$} & \multicolumn{2}{|c|}{ AWA } & \multicolumn{2}{|c|}{ HRWRA } & \multirow{2}{*}{$\begin{array}{c}\text { Tank } \\
\text { Clouding } \\
(\%)\end{array}$} & \multirow{2}{*}{$\begin{array}{c}\text { Washout } \\
\text { Fraction } \\
(\%)\end{array}$} \\
\hline & (cm) & (in.) & & Type & Mass (g) & Type & Mass (g) & & \\
\hline 4 & 25.4 & 10 & 1,000 & ... & ... & ... & ... & 50 & 0.809 \\
\hline 10 & 25.4 & 10 & 700 & UW 450 & 14.6 & 2000-B & 18.65 & 33 & 0.013 \\
\hline 16 & 27.9 & 11 & 1,000 & UW 450 & 14.6 & 2000-B & 7.6 & 20 & 0.021 \\
\hline 19 & 27.9 & 11 & 1,100 & UW 450 & 14.6 & ... & ... & 20 & 0.013 \\
\hline 22 & 22.9 & 9 & 800 & $100 \mathrm{SC}$ & 14.0 & $10 \mathrm{ESL}$ & 7.4 & 60 & 0.830 \\
\hline 30 & 27.9 & 11 & 900 & $100 \mathrm{SC}$ & 18.0 & $10 \mathrm{ESL}$ & 3.6 & 70 & 1.616 \\
\hline
\end{tabular}

TABLE 2 - Test results with nominal $30 \mathrm{~cm}$ (12 in.) consistency flow diameter

\begin{tabular}{|c|c|c|c|c|c|c|c|c|c|}
\hline \multirow{2}{*}{$\begin{array}{c}\text { Mixture } \\
\#\end{array}$} & \multicolumn{2}{|c|}{$\begin{array}{l}\text { Consistency } \\
\text { Diameter }\end{array}$} & \multirow{2}{*}{$\begin{array}{l}\text { Water } \\
(\mathrm{mL})\end{array}$} & \multicolumn{2}{|c|}{ AWA } & \multicolumn{2}{|c|}{ HRWRA } & \multirow{2}{*}{$\begin{array}{c}\text { Tank } \\
\text { Clouding } \\
(\%)\end{array}$} & \multirow{2}{*}{$\begin{array}{c}\text { Washou } \\
\text { Fraction } \\
(\%)\end{array}$} \\
\hline & $(\mathrm{cm})$ & (in.) & & Type & Mass (g) & Type & Mass (g) & & \\
\hline 3 & 30.5 & 12 & 1,050 & ... & ... & $\ldots$ & $\ldots$ & 50 & 1.190 \\
\hline 7 & 30.5 & 12 & 815 & UW 450 & 14.6 & 2000-B & 18.65 & 50 & 0.020 \\
\hline 15 & 33.0 & 13 & 1,100 & UW 450 & 14.6 & 2000-B & 7.6 & 25 & 0.042 \\
\hline 21 & 30.5 & 12 & 1,100 & UW 450 & 14.6 & ... & $\ldots$ & 20 & 0.214 \\
\hline 33 & 30.5 & 12 & 1,000 & $100 \mathrm{SC}$ & 22.0 & ... & ... & 35 & 0.318 \\
\hline 36 & 33.0 & 13 & 950 & $100 \mathrm{SC}$ & 22.0 & $10 \mathrm{ESL}$ & 7.4 & 25 & 0.042 \\
\hline
\end{tabular}

TABLE 3 - Test results with nominal $35 \mathrm{~cm}$ (14 in.) consistency flow diameter

\begin{tabular}{|c|c|c|c|c|c|c|c|c|c|}
\hline \multirow{2}{*}{$\begin{array}{c}\text { Mixture } \\
\quad \#\end{array}$} & \multicolumn{2}{|c|}{$\begin{array}{l}\text { Consistency } \\
\text { Diameter }\end{array}$} & \multirow{2}{*}{$\begin{array}{l}\text { Water } \\
(\mathrm{mL})\end{array}$} & \multicolumn{2}{|c|}{ AWA } & \multicolumn{2}{|c|}{ HRWRA } & \multirow{2}{*}{$\begin{array}{c}\text { Tank } \\
\text { Clouding } \\
(\%)\end{array}$} & \multirow{2}{*}{$\begin{array}{l}\text { Washout } \\
\text { Fraction } \\
\text { (\%) }\end{array}$} \\
\hline & $(\mathrm{cm})$ & (in.) & & Type & Mass (g) & Type & Mass (g) & & \\
\hline 2 & 38.0 & 15 & 1,200 & ... & ... & $\ldots$ & ... & 75 & 4.772 \\
\hline 6 & 35.6 & 14 & 900 & UW 450 & 14.6 & $2000-B$ & 18.65 & 25 & 0.114 \\
\hline 18 & 35.6 & 14 & 1,200 & UW 450 & 14.6 & ... & ... & 40 & 0.200 \\
\hline 26 & 35.6 & 14 & 1,000 & $100 \mathrm{SC}$ & 14.0 & $10 \mathrm{ESL}$ & 7.4 & 50 & 0.917 \\
\hline 27 & 35.6 & 14 & 1,000 & $100 \mathrm{SC}$ & 18.0 & $10 \mathrm{ESL}$ & 7.4 & 20 & 0.011 \\
\hline 29 & 35.6 & 14 & 1,100 & $100 \mathrm{SC}$ & 18.0 & $\ldots$ & $\ldots$ & 30 & 0.073 \\
\hline
\end{tabular}


TABLE 4 - Test results with nominal $40 \mathrm{~cm}$ (16 in.) or greater consistency flow diameter

\begin{tabular}{|c|c|c|c|c|c|c|c|c|c|}
\hline \multirow{2}{*}{$\begin{array}{c}\text { Mixture } \\
\#\end{array}$} & \multicolumn{2}{|c|}{$\begin{array}{l}\text { Consistency } \\
\text { Diameter }\end{array}$} & \multirow{2}{*}{$\begin{array}{c}\text { Water } \\
(\mathrm{mL})\end{array}$} & \multicolumn{2}{|c|}{ AWA } & \multicolumn{2}{|c|}{ HRWRA } & \multirow{2}{*}{$\begin{array}{l}\text { Tank } \\
\text { Clouding } \\
(\%)\end{array}$} & \multirow{2}{*}{$\begin{array}{l}\text { Washout } \\
\text { Fraction } \\
\text { (\%) }\end{array}$} \\
\hline & $(\mathrm{cm})$ & (in.) & & Type & Mass (g) & Type & Mass (g) & & \\
\hline 1 & 45.7 & 18 & 1,300 & $\ldots$ & ... & $\ldots$ & $\ldots$ & 75 & 6.082 \\
\hline 5 & 40.6 & 16 & 1,100 & UW 450 & 14.6 & 2000-B & 18.65 & 25 & 0.152 \\
\hline 17 & 38.0 & 15 & 1,300 & UW 450 & 14.6 & ... & ... & 50 & 0.616 \\
\hline 25 & 38.0 & 15 & 1,100 & $100 \mathrm{SC}$ & 14.0 & $10 \mathrm{ESL}$ & 3.7 & 40 & 0.124 \\
\hline
\end{tabular}

One test was conducted using an admixture "under development" by the manufacturer to enhance pumpability to determine its effect on washout. The results of the test using the same test mixture as \#27 with the addition of the Sika Pump are shown in table 5.

TABLE 5 - Test results using pump enhancement mixture

\begin{tabular}{|c|c|c|c|c|c|c|c|c|c|c|}
\hline \multirow{2}{*}{$\begin{array}{c}\text { Mixture } \\
\#\end{array}$} & \multicolumn{2}{|c|}{$\begin{array}{l}\text { Consistency } \\
\text { Diameter }\end{array}$} & \multirow{2}{*}{$\begin{array}{l}\text { Water } \\
\text { (mL) }\end{array}$} & \multicolumn{2}{|c|}{ AWA } & \multicolumn{2}{|c|}{ HRWRA } & \multirow{2}{*}{$\begin{array}{c}\text { Sika } \\
\text { Pump } \\
\text { Mass (g) }\end{array}$} & \multirow{2}{*}{$\begin{array}{c}\text { Tank } \\
\text { Clouding } \\
(\%)\end{array}$} & \multirow{2}{*}{$\begin{array}{c}\text { Washout } \\
\text { Fraction } \\
(\%)\end{array}$} \\
\hline & (cm) & (in.) & & Type & Mass (g) & Type & Mass (g) & & & \\
\hline 35 & 35.6 & 14 & 1,000 & $100 \mathrm{SC}$ & 18.0 & $10 \mathrm{ESL}$ & 7.4 & 3.6 & 55 & 0.712 \\
\hline
\end{tabular}

Washout tests were also conducted using the test rig to simulate a proposed direct CLSM injection technique for remediation of an inundated vault. These tests were executed to determine the washout resulting from placing the fill tube near a corner of the vault. The process is as follows: (1) start the injection process to build a mound of admixture enhanced CLSM, (2) allow the injecting material to embed the fill tube within the mound, and, (3) continue the fill process until the prescribed quantity of material has been pumped. These tests were conducted using optimized anti-washout admixtures from each of the two suppliers' products (mixtures \#7 and \#27) and are shown in Table 6.

TABLE 6 - Test results with direct injection

\begin{tabular}{|c|c|c|c|c|c|c|c|c|c|}
\hline \multirow{2}{*}{$\begin{array}{c}\text { Mixture } \\
\# \\
\end{array}$} & \multicolumn{2}{|c|}{$\begin{array}{l}\text { Consistency } \\
\text { Diameter }\end{array}$} & \multirow{2}{*}{$\begin{array}{c}\text { Water } \\
\text { (mL) }\end{array}$} & \multicolumn{2}{|c|}{ AWA } & \multicolumn{2}{|c|}{ HRWRA } & \multirow{2}{*}{$\begin{array}{c}\text { Tank } \\
\text { Clouding } \\
\text { (\%) }\end{array}$} & \multirow{2}{*}{$\begin{array}{c}\text { Washout } \\
\text { Fraction } \\
(\%)\end{array}$} \\
\hline & $(\mathrm{cm})$ & (in.) & & Type & Mass (g) & Type & Mass (g) & & \\
\hline 39 & 33.0 & 13 & 815 & UW 450 & 14.6 & 2000-B & 18.65 & 30 & 0.043 \\
\hline 40 & 35.6 & 14 & 1,000 & $100 \mathrm{SC}$ & 18.0 & $10 \mathrm{ESL}$ & 7.4 & 1 & 0.000 \\
\hline
\end{tabular}

\section{Discussion of Results}

The tests indicate that the admixtures enhance the resistance of CLSM to washout. However, the quantity and ratio of AWA to HRWRA are relatively sensitive. The filling of a tank, vault, or canal to a satiated condition requires a very flowable material. When the structure to be remediated is equipped with internal appurtenances and is also 
inundated, the property of flowability is of paramount importance. The specific gravity of CLSM is approximately 2.1 , and when immersed in water (sp gr $=1.0$ ), the forces of gravity which drive self leveling are reduced to approximately half that of an air environment. An admixture-enhanced CLSM mixture with a modified flow consistency diameter of 30-35 cm (12-14 in.) should allow an inundated tank, vault, or canal to be filled to satiation (without requiring the labor intensive task of continually moving the injection tube to reach and fill all "nooks and crannies" within the structure). As the washout data indicates, the admixtures will reduce washout by a factor of approximately 50 and can be essentially eliminated by direct injection (or an equally careful placement technique).

Observation of the CLSM during the mixing process and during the execution of the consistency tests indicated that admixtures favorably affect the flowability of the enhanced material. During mixing, even a very small quantity of HRWRA immediately and abruptly causes the material to behave much more "liquid." However, the addition of the AWA somewhat reverses this effect. During the consistency portion of all the baseline tests, the CLSM would quickly "plop" to its equilibrium diameter. However, the admixture-enhanced CLSM would flow smoothly and deliberately toward the equilibrium diameter, sometimes requiring 20 seconds to reach its final "ceasing of creep" diameter. The admixtures from both suppliers exhibited this behavior in all admixture-enhanced tests (with or without HRWRA).

An interesting phenomenon occurred during all the washout tests. As pointed out, the test tank was filled and allowed to settle to a quiescent state before the injection process was initiated. During the injection phase of the test, a cloud (or fog) raised from the injected material and spread evenly throughout the tank, causing a stratification of adulterated water from the clear water. A distinct interface was observed which separated the two regions. It appeared that the adulterated water was of slightly higher specific gravity, although tests were not conducted to verify this. The color of the adulterated water varied depending on the quantity of washed-out material (from very dark gray to a light white/gray coloration). The same color intensity remained until the test was terminated, allowing approximately 15 minutes of observation. It appeared that the heavier solid suspended materials rapidly settled, but the lighter materials seemed to hang in equilibrium. A sample from mixture \#7 was collected in a bottle and observed for several days. During this period some settlement occurred, but the white/gray fog remained. No confirmation was conducted, but it is surmised that this white/gray cloud resulted from admixture washout (the admixtures all have a sp $\mathrm{gr}>1.0$ ). During direct injection test \#40, very little clouding occurred. Study of the Material Safety Data Sheet indicates that the constituents of the admixtures present little hazard to the environment or human safety, particularly in the concentrations present in the fog layer. Verification may require a separate evaluation.

\section{CONCLUSIONS}

The construction industry uses CLSM routinely, and its applications and material properties are well understood. Anti-washout and high-range water-reducing admixtures 
have been designed, developed, and used to control washout and to improve the water-to-cement ratio with high-strength concrete materials. However, little investigation has occurred for using these admixtures in a low cementitious content CLSM to minimize washout. The test rig developed for this study optimizes the important parameters affecting washout of cementitious materials from CLSM during its injection into an inundated tank, vault, or canal. The model was designed and built to simulate the procedures proposed to remediate inundated tanks, vaults, and canals at ORNL.

Particular attention was focused on the compatibility of geometric and dynamic similitude of the model, with available commercial equipment proposed for the injection process of admixture-enhanced CLSM.

Test results indicate that washout contamination of the inundated tank fluid and cross-contamination of the CLSM with tankage inventory will be minimized by using admixture-enhanced CLSM. A ground rule for this program is that the CLSM developed must maintain a free-flowing characteristic. This allows the material to satiate the structure's volume by filling all voids and appurtenances and by effectively sealing all entrances and exits. An admixture-enhanced CLSM with a modified flow consistency test diameter of 30-35 cm (12-14 in.) inches should meet this stipulation for current tank, vault, and canal remediation applications. Trial mixtures \#7 and \#27 proved to be reproducible and resulted in minimized washout. Table 7 provides an extrapolation of each of these tests' constituents to a cubic yard commercial batch.

Table 7 - Extrapolation of test results to commercial batch parameters

\begin{tabular}{|l|c|c|}
\hline \multicolumn{1}{|c|}{ Constituent } & \#7 Test & \#27 Test \\
\hline Modified Flow Consistency Test & $12 \mathrm{in}$. & $14 \mathrm{in}$. \\
\hline Portland Cement (Type I, or II) & $55 \mathrm{lb}$ & $55 \mathrm{lb}$ \\
\hline Fly Ash (Type F) & $650 \mathrm{lb}$ & $650 \mathrm{lb}$ \\
\hline $\begin{array}{l}\text { Dry Concrete Sand } \\
\text { (manufactured or river run) }\end{array}$ & $2400 \mathrm{lb}$ & $2400 \mathrm{lb}$ \\
\hline Water & $625 \mathrm{lb}(75.0$ gal) & $765 \mathrm{lb}(91.7$ gal) \\
\hline Water/(Cementitious Materials) & 0.88 & 1.09 \\
\hline Admixtures & \multicolumn{2}{|c|}{} \\
\hline Commercial Supplier & Master Builder, Inc. & Sika Corporation \\
\hline Anti-washout & $\begin{array}{c}\text { Rheomac UW 450 } \\
11.18 \mathrm{lb}(1.1 \text { gal) }\end{array}$ & $\begin{array}{c}\text { Sikament 100 SC } \\
10.7 \mathrm{lb}(1 \text { gal) }\end{array}$ \\
\hline High Range Water Reducing & $\begin{array}{c}\text { Rheobuild 2000-B } \\
14.3 \mathrm{lb}(1.36 \text { gal) }\end{array}$ & $\begin{array}{c}\text { Sikament 10 ESL } \\
5.67 \mathrm{lb}(0.61 \text { gal) }\end{array}$ \\
\hline
\end{tabular}

In specifying a commercially supplied admixture-enhanced CLSM, it is recommended that the quantities of cement, fly ash, dry sand, AWA, and HRWRA be specified by weight or volume and that the desired modified flow consistency test diameter be specified. The commercial supplier of the admixture-enhanced CLSM determines the quantity of water to be used. To control all parameters during this 
program, all the trial mix tests used very dry constituents. Each of the dry constituents was carefully sifted through a sieve before being weighed and mixed. The commercial supplier will use raw materials as they exist at the batch plant, which implies that they will contain an appreciable amount of water (e.g., concrete sand normally contains about $2 \%$ water by weight).

An important parameter controlling the washout is the ratio of the quantity of AWA to HRWRA and the total mass ratio of admixtures (AWA plus HRWRA) to the cementitious materials (cement plus fly ash):

$$
\frac{M_{\text {AWA }}+M_{\text {HRWRA }}}{M_{\text {Cement }}+M_{\text {Fly Ash }}}=\text { Admixture Mass Ratio }
$$

Therefore, if it is deemed necessary to change the strength of an admixture-enhanced CLSM by adding or reducing the cement or fly ash, then holding this mass ratio constant should provide similar washout characteristics to the original mix.

\section{ACKNOWLEDGMENTS}

This work was performed at the Oak Ridge National Laboratory, Oak Ridge, Tennessee and was supported by the United States Department of Energy under Contract DE-AC05-84OR21400. Neither the United States Government nor any agency thereof, nor any of their employees, makes any warranty, express or implied, or assumes any liability or responsibility for the accuracy, completeness, or usefulness of any information, apparatus, product, or process disclosed, or represents that its use would not infringe privately owned rights. The views and opinions of the authors expressed herein do not necessarily state or reflect those of the United States Government or any agency thereof.

The authors acknowledge the assistance provided by Pam Groves, Larry Hawk, Peter Souza, and Jaminn Pricer, all of the Oak Ridge National Laboratory, for their assistance in the testing. The authors also acknowledge Master Builders, Inc. and Sika Corporation for providing comments on the use of their products and for participating in the washout and consistency testing of their products.

\section{REFERENCES}

[1] Khayat, K. H. and W. T. Hester, "Evaluation of Concrete Mixtures for Underwater Pile Repairs," Cement, Concrete, and Aggregates, ASTM CCAGDP, Vol 13, No. 1, Summer 1991, p. 32. 
[2] Standard Test Method for Measurement of Hydraulic Conductivity of Saturated Porous Material Using a Flexible Wall Permeameter, ASTM Designation: D 5084 90; June 28, 1990.

[3] Test Method for Permeability of Concrete Using Triaxial Cell, Corps of Engineers Standards CRD-C 163-92, September 1, 1992.

4] Controlled Low Strength Materials (CLSM), American Concrete Institute (ACI) Report 229R-94, 1994 CLSM Committee Report, ACI Concrete International, July 1994, p. 55.

[5] Khayat, K. H., "Effects of Antiwashout Admixtures on Fresh Concrete Properties," ACI Materials Journal, March-April 1995, p. 164.

[6] Handbook for Concrete, U.S. Army Waterways Experiment Station, Vicksburg, MS, 1949.

[7] “Washing Out Test," Technical Report No. 3, Hydro-Beton, Belgium, 1982. 